\title{
Penerapan Edmodo bagi Guru dan Murid SMK Karya Bhakti Brebes sebagai Media Belajar Tambahan
}

\author{
The Implementation of Edmodo for Teachers and Students of SMK Karya Bhakti Brebes \\ as Additional Learning Media English \\ Ramadhan Rakhmat Sani ${ }^{1}$, Danang Wahyu Utomo ${ }^{2}$, Defri Kurniawan ${ }^{3}$ \\ ${ }_{1,2,3}^{13}$ Fakultas Ilmu Komputer, Universitas Dian Nuswantoro \\ E-mail: ${ }^{1}$ ramadhan rs@dsn.dinus.ac.id, ${ }^{2}$ danang.wu@dsn.dinus.ac.id, \\ 3̄efri.kurniawan@dsn.dinus.ac.id
}

\begin{abstract}
Abstrak
Berkembangnya teknologi secara masif memberikan pengaruh salah dalam dunia pendidikan. Para guru perlu mengimbangi perkembangan teknologi dari siswanya yang sangat mudah dalam mengabdospinya. Pembelajaran online sudah banyak diterapkan pada banyak sekolah tetapi hanya tidak jarang juga yang diterapkan oleh para guru untuk melaksanakannya. Salah satunya adalah SMK Karya Bhakti Brebes yang sudah mengetahui tentang e-learning tetapi hanya beberapa mata pelajaran saja dalam penerapannya. Dalam penerapan pembelajaran online terkadang para guru masih kesulitan dalam mengatur kelasnya. Maka dari itu diperlukan pendampingan dalam penggunaan sistem e-learning salah satunya adalah edmodo. Dan juga sosialisasi terhadap guru-guru lainya untuk mendapatkan pemahaman khusus dalam proses pembelajaran online seperti dalam melakukan ulangan harian ataupun penugasan. Hasil dari pengabdian ini memberikan pemahaman khusus dasar aplikasi tersebut dan bagaimana proses pengisian konten yang dilakukan bagi para guru dengan melakuan simulasi langsung.

Kata kunci: e-learning, edmodo, guru, SMK Karya Bhakti
\end{abstract}

Abstract
The development of technology has a massive influence on the world of education. Teachers need to balance the technological development of their students who are very easy to devote. Online learning has been widely applied in many schools but it is not infrequently also implemented by teachers to implement it. One of them is SMK Karya Bhakti Brebes who already knows about e-learning but only a few subjects in its application. In the application of online learning, sometimes teachers still have difficulty managing their classes. Therefore, assistance is needed in the use of e-learning systems, one of which is edmodo. And also the socialization of other teachers to get a special understanding in the online learning process such as doing daily tests or assignments. The results of this service provide a special understanding of the basic application and how the content filling process is done for teachers by conducting direct simulations.

Keywords: e-learning, edmodo, teacher, SMK Karya Bhakti

\section{PENDAHULUAN}

Dalam kegiatan belajar mengajar, guru memiliki peran penting dalam mengembangkan proses pembelajaran. Guru tidak hanya mengajar siswa tetapi juga bertugas dalam membina, memberi contoh, dan mengevaluasi. Oleh karena itu, guru dituntut untuk mampu mengembangkan kemampuannya meliputi tiga aspek yaitu kognitif, afektif dan psikomotorik. Tentunya pengembangan diri tidak lepas dari infrastruktur pendukung dari sekolah. Perlu adanya peran pendukung kepada guru untuk meningkatkan tiga aspek pembelajaran tersebut 
seperti media pembelajaran (whiteboard, projector, peta, komputer). Jika guru masih menggunakan cara konvensional dalam mengajar yaitu pembelajaran satu arah, siswa hanya mendengarkan apa yang guru jelaskan. Akibatnya, tidak semua siswa dapat memahami apa yang guru jelaskan dikarenakan siswa mulai bosan, ngantuk, bahkan suka berbicara dengan teman sebelahnya. Perlu adanya inovasi dalam pembelajaran di kelas.

Teknologi yang berkembang saat ini membawa pengaruh bagi model pengajaran dalam pendidikan formal. Tingginya penggunaan internet sudah menjadi kebutuhan yang tidak bisa dilepaskan dalam penggunaan smartphone, komputer dan peralatan lainnya. Sehingga berdampak terhadap banyaknya e-learning dalam dunia pendidikan yang berkembang yang dapat meningkatkan motivasi dan hasil belajar bagi para siswa [1]. Dimana salah satu tujuan adanya e-learning yaitu mampu membantu para pengajar dalam memberikan inovasi dalam proses belajar mengajar di kelas. Guru dapat memantau perkembangan dari siswanya, guru dapat mengatur pemberian tugas secara berkala, dan siswa pun dapat selalu mengecek nilai yang diperoleh selama pembelajaran [2]. Namun, permasalahan yang terjadi saat ini adalah mayoritas para pendidik masih beranggapan bahwa metode konvensional masih metode paling baik dalam proses KBM. Pendidik memiliki anggapan bahwa pembelajaran yang baik adalah pembelajaran yang bertatap muka, siswa mendengarkan dan memahami apa yang guru jelaskan, dan siswa diharuskan bertanya jika masih bingung dengan materi yang dijelaskan. Selain itu, kendala yang kedua adalah usia yaitu mayoritas para pendidik yang sudah tua lebih memilih metode yang selama ini digunakan daripada harus mempelajari lagi teknologi baru (e-learning). Namun masih saja ada guru yang kesulitan menggunakan dasar e-learning di KBM seperti pada SMK Karya Bhakti Brebes dan belum adanya konten - konten yang ditentukan dalam e-learning. [3] menyatakan bahwa aspek manusia penting dalam penyelenggaraan KBM. Motivasi, kognitif, dan profesionalitas penting dalam meningkatkan kualitas belajar siswa. Seorang pendidik seharusnya mampu memberikan inovasi dan mengikuti perkembangan teknologi yang telah berkembang. Para siswa saat ini sudah familiar dengan perkembangan teknologi saat ini. Mayoritas siswa sudah mengenali perkembangan internet, memiliki smartphone, dan sosial media sebagai komunikasi.

Salah satu e-learning tersebut adalah Edmodo yang merupakan Aplikasi online yang sangat populer di kalangan guru karena dapat memudahkan pekerjaan mereka sehari-hari [4][5]. Layanan seperti Edmodo sendiri dikenal dengan nama Learning Management System (LMS). Aplikasi ini biasa digunakan baik ketika guru berada di dalam maupun luar kelas. Aplikasi ini dirancang dengan fokus kepada guru, karena siswa dan orang tua hanya bisa login dengan Edmodo jika mendapat undangan dari guru.Berdasarkan permasalahan diatas, perlu adanya tindak lanjut kembali dalam penggunaan edmodo yang diusulkan. Perlu adanya pendampingan dan pemahaman bagi guru - guru agar dapat menjalankan edmodo.

\section{METODE PELAKSANAAN}

Pelaksanaan pengabdian masyarakat diawali dengan melakukan koordinasi dengan pihak SMK Karya Bhakti Brebes yang terdiri dari Kepala sekolah dan wakil Sekolah untuk menentukan mekanisme pelaksaan pengabdian masyarakat. Penentuan jumlah guru peserta pelatihan, waktu dan tempat pelaksanaan pelatihan. Penyebaran undangan pelatihan ke guru-guru SMK Karya Bhakti Brebes. Pembentukan tim dan pembagian tugas anggota tim pengabdian masyarakat. Persiapan teknis pelaksanaan bersifat fisik antara lain: komputer, LCD projector, peralatan dokumentasi, backdrop, konsumsi, materi pelatihan (printed), kuisioner, dan daftar hadir peserta. Persiapan teknis pelaksanaan bersifat non-fisik antara lain: aplikasi sistem ujian, materi presentasi pelatihan (soft-copy), dan koneksi internet. Pelaksanaan kegiatan pengabdian masyarakat dan dokumentasi kegiatan. Kemudian Penyusunan laporan pertanggungjawaban kegiatan dan yang terakhir adalah pembubaran tim dan evaluasi kegiatan pengabdian masyarakat. 
Pada gambar 1 mengambarkan alur singkat bagaimana pelaksanaan IbM Pemanfaatan Edmodo bagi Guru dan Murid SMK Karya Bhakti Brebes sebagai Media Belajar Tambahan yang dilaksanakan dimulai dari koordinasi awal, pembentukan tim, pelaksanaan hingga penulisan laporan.

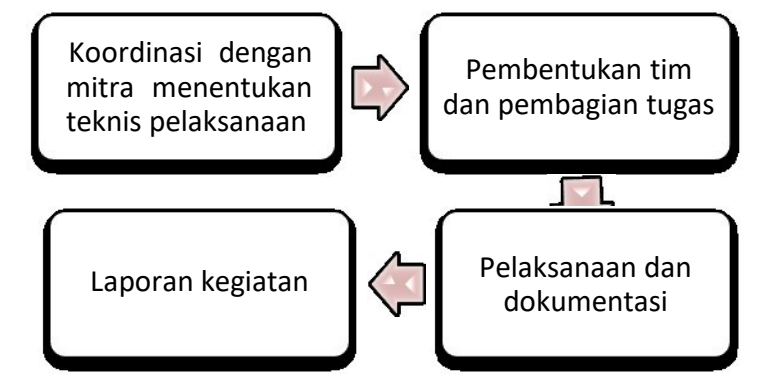

Gambar 1 Tahapan / langkah-langkah Pelaksanaan Kegiatan

\section{HASIL DAN PEMBAHASAN}

Kegiatan Ipteks bagi Masyarakat (IbM) dapat diselenggarakan atas kerjasama Tim Pengabdian Universitas Dian Nuswantoro (UDINUS) dengan Murid SMK Karya Bhakti Brebes yang telah berkomitmen sebagai mitra. Walaupun pelaksanaan IbM memiliki keterbatasan waktu dan tempat, namun kegiatan dapat tetap berjalan.

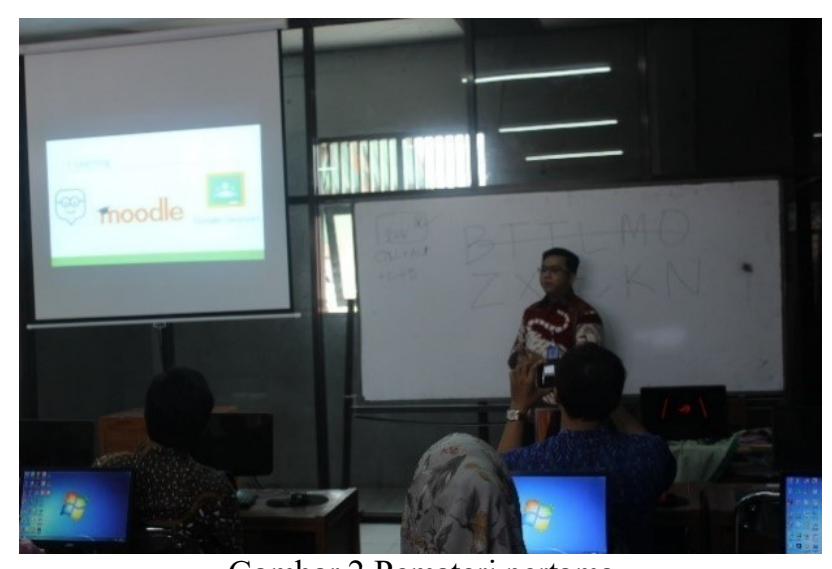

Gambar 2 Pemateri pertama

Kegiatan ini diawali sambutan dan perkenalan dari tim Abdimas yang diwakili oleh bapak Danang Wahyu Utomo yang tampak pada gambar 2 sekaligus memperkenalkan materi tentang e-learning dan beberapa contoh yang sering digunakan seperti Edmodo beserta flatfom apa saja yang bisa dipakai. 


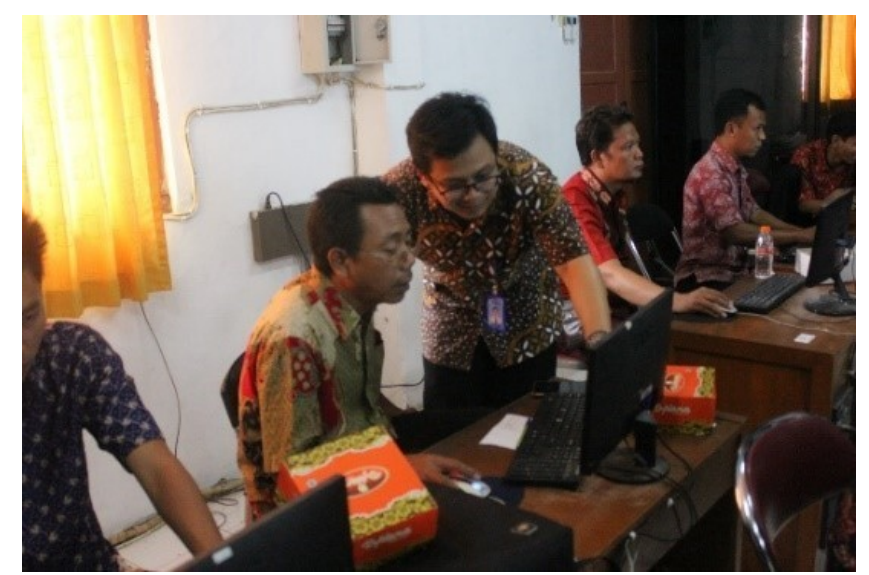

Gambar 3 Pemateri kedua

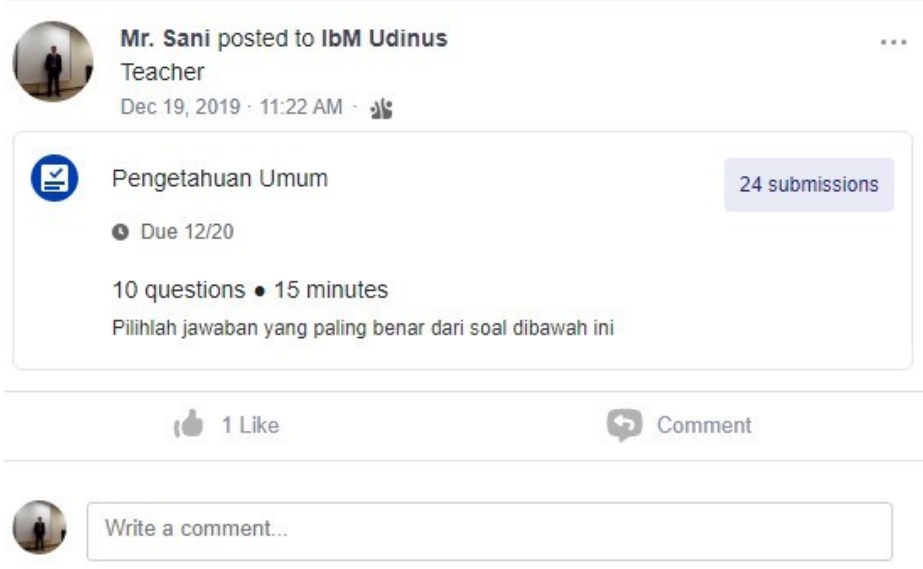

Gambar 4 melakukan Pengrahan

Materi kedua disampaikan oleh bapak Defri Kurniawan tampak pada gambar 3 menerangkan dan mempraktekan Edmodo yang digunakan dalam vers web dimana guru bisa melakukan login atau pendaftaran sebagai guru bagi yang belum memiliki akun. Dan selanjutma membuat kelas, pengaturan quiz, membuat kelas dan penugasan. Pada bagian ini mensimulasikan bagaimana guru sebagai murid mengerjakan soal yang sudah dipersiapkan. Pertanyaan sudah dipersiapkan sebelum kegiatan dimulai, berisikan 10 soal pengetahuan umum dengan tipe pilihan ganda yang dibatasi waktu 10 menit pada gambar 4. Pada saat berlangsunnya kegiatan para guru dipersilahkan untuk mencoba proses menjawab soal pilihan ganda.
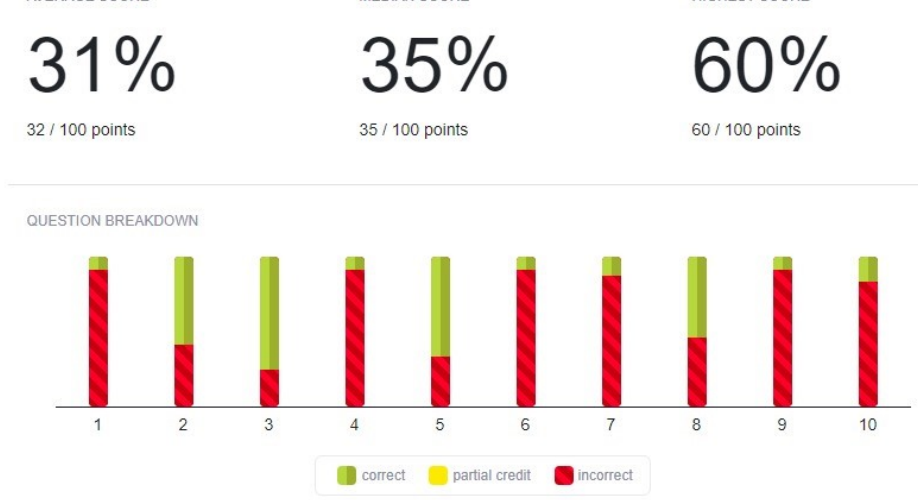
Gambar 5 Hasil tiap-tiap soal yang dijawab benar oleh guru

Hasil yang didapat pada semua pertanyaannya dituangkan dalam gambar 5 yang menunjukan prosentase jumlah benar yang didapat oleh para guru, dimana nilai paling tinggi adalah $60 \%$ dari semua soal, rata sebesar $35 \%$ dan yang paling rendah $31 \%$ dari semua total soal yang diikuti oleh 24 guru yang mengumpulkan jawabannya.

Materi ketiga disampaikan oleh bapak Ramadhan Rakhmat Sani yang tampak pada gambar 6 tentang penerapan edmodo dengan menggunakan versi mobile yang tidak jauh berbeda juga dengan yang versi web. Akan tetapi versi ini akan lebih berguna apabila guru sedang dalam kondisi tidak berada di sekolah atau pun sedang ada tugas.

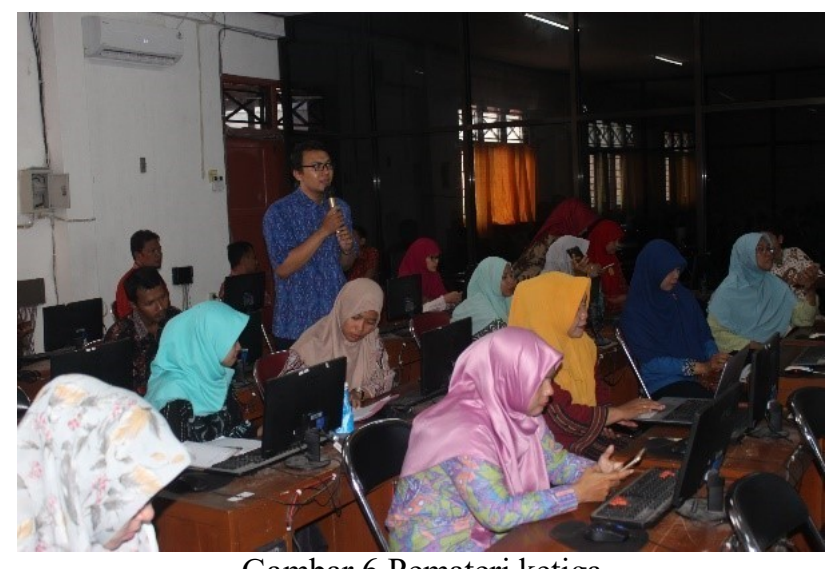

Gambar 6 Pemateri ketiga

Pada bagian difokuskan agar para guru mensimulasikan dari pembuatan kelas, membuat soal dan mendistribusikan kepada anggota kelas. Pada gambar 7 merupakan beranda yang menampilkan postingan oleh salah satu guru yang telah membuat soal dalam kelas untuk dikerjakan oleh anggota yang berada dalam kelas.

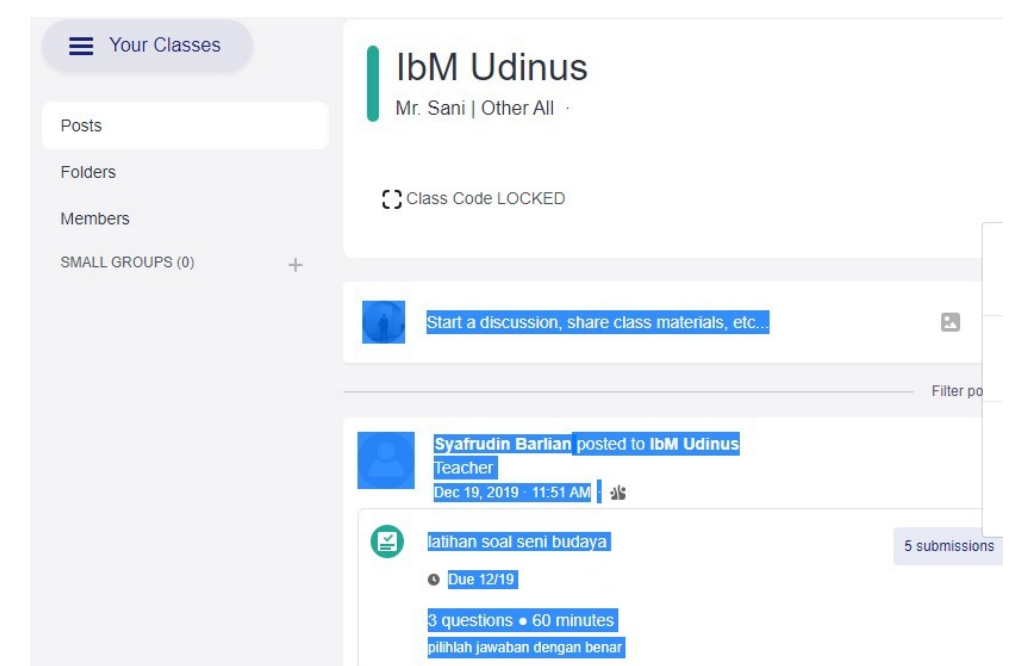

Gambar 7 Percobaan membuat pengumuman mengerjakan soal oleh guru

\section{KESIMPULAN DAN SARAN}

Kegiatan Ipteks bagi Masyarakat (IBM) dalam bentuk pelatihan dan simulasi penggunaan Edmodo sebagai bahan pembelajaran tambahan berjalan dengan lancer tak terlepas 
terdapat beberapa kekurangan seperti waktu pelaksanaan yang terbatas. Pelatihan memberikan manfaat berupa pengetahuan dan skill dalam mensimulasikan aplikasi edmodo yang dapat digunakan oleh para guru pengampu dalam mengevaluasi penyerapan materi ajar para siswa di kelas.

Sehingga untuk kedepannya bisa digunakan oleh para guru sebagai media tambahan dan apabila sedang berhalangan hadir di sekolah

\section{UCAPAN TERIMA KASIH}

Penulis mengucapkan terima kasih kepada Lembaga Penelitian dan Pengabdian Masyarakat (LPPM) Universitas Dian Nuswantoro yang telah memberikan dukungan melalui pendanaan dalam kegiatan pengabdian ini. Tidak lupa juga kepada SMK Karya Bhakti Brebes yang bersedia menjadi mitra sehingga dapat terlaksananya kegitan ini.

\section{DAFTAR PUSTAKA}

[1] Rosyidah, T. Kartini, and S. Kantun, "Rosyidah, Titin Kartini, Sri Kantun," J. Ilm. Ilmu Pendidikan, Ilmu Ekon. dan Ilmu Sos., vol. 13, no. 2018, pp. 78-84, 2019, doi: 10.19184/jpe.v13i2.10878.

[2] S. N. Hutagalung, "Media Pembelajaran Pembuatan Quiz Fisika (Wondershare Quizcreator Dan Edmodo )," in Seminar Nasional Sains \& Teknologi Informasi (SENSASI), 2019, pp. 626-629.

[3] I. Hadar, S. Sherman, and O. Hazzan, "Learning human aspects of collaborative software development," J. Inf. Syst. Educ., vol. 19, no. 3, pp. 311-320, 2007.

[4] E. Santoso, "Kelas Virtual Menggunakan E-Learning Berbasis Edmodo ( Virtual Classes Using E-Learning E Learning Based on Edmodo )," J. THEOREMS (The Orig. Res. Math., vol. 3, no. 2, pp. 169-177, 2019.

[5] L. N. Aulia, S. Susilo, and B. Subali, "Upaya peningkatan kemandirian belajar siswa dengan model problembased learning berbantuan media Edmodo," J. Inov. Pendidik. IPA, vol. 5, no. 1, pp. 69-78, 2019. 